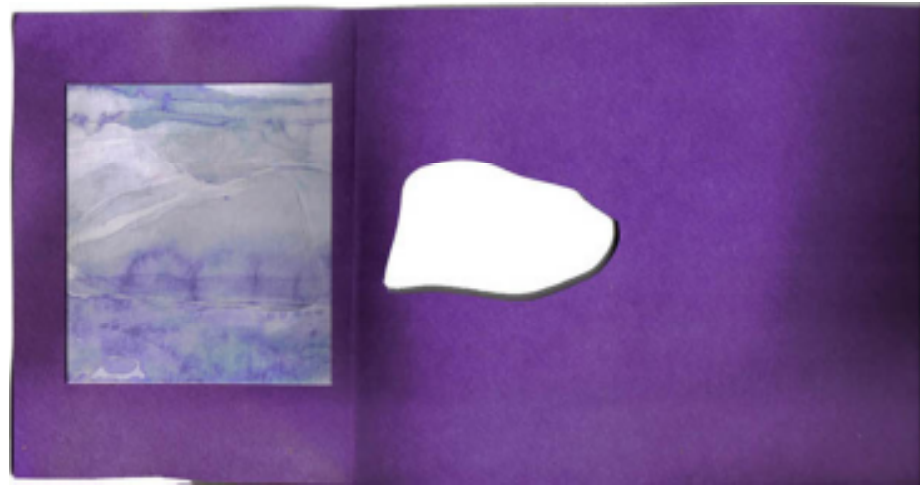

Ilustração Juliana Ramos

\title{
Poesia e tradução entre Brasil e Argentina
}

\author{
Rodolfo Alonso \\ por Vivaldo Lima Trindade (Brasil)
}

Rodolfo Alonso tinha apenas dezesseis anos quando conheceu e integrou o grupo em torno da revista Poesía Buenos Aires. Nesse tempo, ainda em 1951, era leitor de Lorca e Neruda, mas admirava principalmente a poesia de César Vallejo. A partir deste encontro com a vanguarda modernista portenha, desenvolveu uma intensa atividade criadora e intelectual, transitando entre a poesia, a tradução e o ensaio. É autor, entre outros, dos livros de poesia Salud o nada (1954), Buenos vientos (1956), Gran Bebé (1960), Hablar claro (1964), Relaciones (1968), Hago el amor (com prólogo de Carlos Drummond de Andrade, 1969), Señora Vida (1979), Sol o sombra (1981), Alrededores (1983), Jazmín del país (1988) e Música concreta (1994). Primer tradutor de Fernando Pessoa na América Latina (1961). No ano de 2003, "en medio del comprensible silencio universal", apareceram seus livros de poesía El arte de callar, publicado pela editora cordobesa Alción, Antologia pessoal - bilíngüe - (Thesaurus, Brasilia) e La otra vida, antología publicada em Bogotá, Colômbia, além de suas versões de Estrella de la vida entera, de Manuel Bandeira (Adriana Hidalgo); El banquero anarquista, de Fernando Pessoa (Emecé), e Poemas escogidos, de Giuseppe Ungaretti (Común Presencia, Bogotá). Recentemente foi agraciado com importantes prêmios por sua atuação literária, dentre eles as Palmas Acadêmicas (concedido pela Academia Brasileira de Letras). 


\begin{abstract}
Vivaldo Lima Trindade - A poesia do senhor já foi definida mais de uma vez como uma poesia do silêncio. O que move 0 senhor a escrever hoje é o mesmo que o movia quando iniciou sua obra poética?
\end{abstract}

Rodolfo Alonso - Em grande parte, sim. Nunca me propus a escrever poesia. É como dizer que meus poemas nunca foram fruto de um projeto, de uma predeterminação, sendo melhor entendidos como acontecimentos dos quais eu era o mediador. Na verdade, bastante ansioso e inseguro. A poesia me ocorre, me acontece. Antes e agora. Claro que, com os anos, esse instrumento, que é o mesmo, teve que amadurecer em algo. E, especialmente na prosa, e também na fala, a insegurança e a ansiedade começaram agora a mostrar-se em grande parte manipuláveis. Porém nunca de todo, claro. E a poesia segue soprando onde quer, como bem disse Murilo Mendes. E quando quer, eu acrescento. Às vezes ocorrem largos intervalos de silêncio e, muito poucas vezes, preparo vários poemas ao mesmo tempo. Eu me deixo levar.

\title{
Poderia falar do que a revista Poesía Buenos Aires significou para o senhor e para a cultura de seu país?
}

Hoje, me resulta árduo separar os domínios pessoal e público. É que eu me aproximei milagrosamente da Poesia Buenos Aires, superando minha inata timidez, uma noite antes de completar meus 17 anos, vindo a me converter, sem ter me proposto, em seu membro mais jovem. E essa lendária revista argentina de vanguarda, absolutamente independente, cujas trinta publicações, entre 1950 e 1960, só foram possíveis graças a seu verdadeiro inspirador e artífice, Raúl Gustavo Aguirre, foi para mim, em plena adolescência, uma autêntica experiência de vida e linguagem. E para a poesia moderna argentina, um marco, que, também sem haver sido proposto, sem compromissos e sem dogmas, veio a instalar indubitavelmente um antes e um depois. Tanto no que fez à minha própria experiência profissional, como à sua mais ampla significação cultural e estética, sinto que posso reiterar seu alcance em duas palavras: fraternidade e exigência. Todos temos o direito a experimentá-la, porém a poesia é uma coisa séria. A mais séria, eu diria.

\section{E como se deu sua aproximação com os escritores brasileiros?}

Com toda a naturalidade. E, ao mesmo tempo, milagrosamente. Minha própria infância bilíngüe, de portenho filho de galegos, implica uma consangüinidade quase orgânica com a língua portuguesa. Minha própria condição de primeiro filho de 
imigrantes nascido em Buenos Aires me pôs diante, não apenas de uma situação teórica, mas também de uma necessidade fisiológica de me voltar não apenas para o solo argentino, mas também para o latino-americano $e$, em conseqüência, me concedeu, assim, desde muito criança, uma profunda e intuitiva afinidade com o Brasil, depois, mais da metade da América Latina, que não tem deixado de seduzir-me desde então. Assim devo a contribuição, sem dúvida, ao meu velho e querido amigo Milton de Lima Sousa, que fora para nós desde sempre um membro a mais da Poesía Buenos Aires. É que nessa revista eu começara a publicar minhas primeiras traduções de Carlos Drummond de Andrade e de Murilo Mendes, com os quais, já por aqueles tempos, e como disse superando uma timidez inata, havia começado a manter um intercâmbio epistolar, insolitamente generoso por parte deles e para mim tão apaixonante quanto fecundo e enriquecedor.

\begin{abstract}
Mais do que no futebol, Brasil e Argentina parecem virados de costas um para o outro também no terreno da cultura, excetuando-se nomes muitíssimo consagrados mundialmente. Qual, na sua opinião, era o ponto de identificação entre as vanguardas modernistas do século passado na América Latina?
\end{abstract}

É verdade, por infortúnio, em grande medida. À balcanização, que entretanto mantém incomunicáveis os países hispanoamericanos entre si e só pode favorecer aos poderes e interesses alheios, se agregam a injustiça e, injustificavelmente, a distância, que todavia se mantém entre quem aqui fala castelhano e o Brasil, que, como disse, é praticamente a metade de nosso continente. Modestamente, sem trégua, e com os modestos meios a meu alcance, tenho aqui tratado sempre de ajudar para que se quebre essa barreira inócua. Porém, voltando à sua pergunta, digamos que esses contatos tampouco foram suficientemente fluidos entre os movimentos latino-americanos de vanguarda no século passado. Houve contatos, sim, porém esporádicos, e na medida em que teriam sido necessários. Destaquemos, ao mesmo tempo, que o termo "modernista", em meios hispano-americanos, representa exatamente o antípoda do que foi o grande movimento modernista brasileiro. Nossas vanguardas reagiram aqui contra a retórica "modernista" como vossos modernistas reagiram aí contra o que as precedeu. E, por infortúnio, que eu saiba, não houve naquele momento demasiados canais de comunicação entre os movimentos renovadores de ambas as línguas. Diferentemente do que foi a acolhida posterior como, por exemplo, em meu caso e no de alguns companheiros, porém não somente ali, é claro. 


\section{- senhor crê que haja muita diferença entre modernistas e pós- modernos? Aliás, seria possível definir quais são as tendências da poesia argentina contemporânea?}

Mais que diferença. Tenho a intuição de que, desde a metade do século passado, e cada vez de maneira mais crescente, estamos vivendo sem nos darmos conta, imersos não em uma mudança, mas sim em uma mutação. A sociedade de consumo vem a somar-se, potencializada pela incessante renovação tecnológica dos meios de sedução de massa, ao que Guy Débord batizou como sociedade do espetáculo, e o resultado é uma "civilização" onde a linguagem tem deixado, é claro, de ser o centro, e cujo objetivo principal é a formação de consumidores acríticos, cuja ansiedade principal é o ato da compra, por outro lado fonte inevitável de nova ansiedade. Uma de suas mais deletérias conseqüências é a perda espontânea da capacidade criadora da linguagem por parte do povo, da comunidade. E, em consequiência, há um retrocesso, se é que não uma deformação do que se entendia por poesia. Lamento seguir parecendo apocalíptico (no meio deste verdadeiro apocalipse da banalidade que nos consome), porém me resulta impossível discernir tendências no meio da enorme massa de textos que hoje se exibe. É como dizer, precisamente, que a ausência absoluta de tendências, não somente na poesia, se não praticamente em todas as artes hoje assoladas pelo avassalador totalitarismo do mercado, me resulta em um alarmante sintoma destes tempos. Foi um de nossos maiores poetas populares, Enrique Santos Discépolo quem, já em 1935, pôde sinalizar, em seu indelével tango Cambalache, que "Tudo é igual... Nada é melhor..." e não muito depois, aquele que Mário de Andrade batizou cabalmente como o "São João Baptista do modernismo", o grande Manuel Bandeira, um homem cuja alta poesia está indissoluvelmente ligada com a linguagem do povo, podia animar-se a afirmar isto: "Sem dúvida não custa nada escrever um pedaço de poesia e depois distribuílo em linhas irregulares, obedecendo tão somente às pautas do pensamento. Porém, isso nunca foi verso livre. Se o fosse, qualquer pessoa poderia pôr em verso até o último pronunciamento do Ministro da Fazenda. Essa enganosa facilidade é causa da superpopulação de poetas que infecta agora nossas letras. O modernismo teve isso de catastrófico: trazendo para nossa língua o verso livre, deu a todo mundo a ilusão de que uma série de linhas desiguais é poema. Resultado: hoje, qualquer sub-escrevente de município, com um pouco de zelo, qualquer ninfeta desiludida com o namorado, qualquer balzaquiana desorientada em seu ambiente familiar, se julgam habilitados para competir com Joaquim Cardozo ou Cecília Meireles." O que nós poderíamos adicionar então, agora? 


\section{E a atual produção em língua portuguesa, o senhor acompanha?}

Dentro do panorama aludido em minha resposta anterior, e com respeito à produção de poesia, percebo, ao mesmo tempo, que têm países que, todavia não têm se afundado na regra geral. Além do Brasil, é claro, com o qual mantenho uma ativa relação, estão os países europeus, um deles é Portugal. Na medida do possível, e com as dificuldades que todos conhecemos (já não há em Buenos Aires aquelas livrarias especializadas em literaturas estrangeiras) e graças a certos amigos e a certas publicações, trato de seguir em contato com a poesia e a literatura que se escreve em português. Quase no mesmo instante que deu inicio minha empatia com o Brasil, e por razões muito similares, me descobri muito jovem traduzindo, também na Poesía Buenos Aires, não apenas Pessoa, naqueles tempos praticamente desconhecido, mas também outros poetas portugueses que estreavam, em meio à noite salazarista, como António Ramos Rosa ou Egito Gonçalves. E até, faz muito pouco tempo, foi algo fundamental para mim o encontro - recente com José Augusto Seabra, um humanista exigente e fraternal, lamentavelmente falecido.

\section{Dentro de uma perspectiva humanista, quais são os maiores desafios para os intelectuais do século XXI?}

Primeiro, é continuar sendo um intelectual. Que, se forem capazes de refletir criticamente no meio deste sedutor pesadelo de banalidade universal, vão se tornar absolutamente imprescindíveis. Por outro lado, intuo que, não somente aos supostos intelectuais, se não, na realidade, a qualquer homem consciente de sua própria condição, será inevitável defrontarse com os gravíssimos problemas de sobrevivência. Os limites do famigerado capitalismo selvagem globalizado já não serão orientados por perspectivas de justiça econômica, política ou social, senão por razões ecológicas elementares: o planeta não suportará. E as graves conseqüências ecológicas não se limitarão à natureza, ao nosso habitat, mas já estão afetando - e desde muito tempo - a própria condição humana. Uma autêntica perspectiva ecológica não só deverá seguir levando muito em conta os danos ao planeta, se não, também, ao mesmo tempo, o custo que tudo isso tem sido para nós, os seres humanos, enquanto espécie.

\section{E a Internet, não seria um espaço de maior democratização, de maior atuação política e intervenção artística?}

Temo que não. Não me parece que a Internet seja inócua, inclusa em si mesma. E, por outro lado, é evidente, está inscrita no marco geral ao que alude minha resposta anterior. 
Neste tema, aqui volto a coincidir com meu admirado e querido amigo Tomás Maldonado, cujo Crítica da razão informática (Barcelona: Paidós, 1998), editado originalmente na Itália e onde praticamente esgota o tema, acabo de reler: "estimo mais provável que um acesso indiscriminado da informação pode conduzir-nos na realidade não a uma forma mais avançada de democracia, se não apenas a uma forma mais sofisticada de controle social e de homologação cultural". Como bem é dito, não é que eu me oponha aos benefícios que as novas tecnologias podem apontar-nos, mas que nos recusemos a suspender, com respeito às suas conseqüências, uma permanente atitude de avaliação crítica. Bom, sei que gente bem intencionada imagina que uma sociedade altamente informatizada poderia nos aproximar de uma maior democracia, mais direcionada, mais profunda. Porém, não deixa de inquietar-me por demais, junto com Maldonado, que "com o fim de publicitar tal cenário, as grandes multinacionais da informática e da comunicação tem posto em marcha uma muito eficiente maquinaria de consenso político-cultural e comercial". Para sintetizá-lo, com extrema clareza, em uma simples nota ao pé da página: "Ou seja, como os proprietários dos meios condicionam as mensagens".

\section{o senhor também se notabilizou enquanto tradutor. Qual poeta the apresentou maiores dificuldades e qual mais the agradou?}

Ainda que tenha intentado desde sempre, coisa que por um lado me parece humanamente irrenunciável, a tradução de uma grande poesia lograda em outra língua será sempre uma utopia. Como bem disse Carlos Mastronardi: "Tudo é traduzível, exceto a linguagem". Eu somente posso encarálla com os poetas e as línguas frente aos quais me sinto em empatia (francês, italiano, português). É dizer que, ainda que me proponham, há textos aos quais tenho renunciado: Mallarmé e Leopardi, por exemplo. E, entre os brasileiros, Mário de Andrade, cuja muito peculiar personalidade lingüística é quase intransferível. Tenho me sentido muito confortável na tradução de Pessoa e também de Drummond de Andrade ou Murilo Mendes. E até com Olavo Bilac, inclusive, ao que houve momentos onde temi frustrar-me frente às exigências imprescindíveis de som e sentido. Entranhar-me em Manuel Bandeira, que me parecia tão acessivel, foi uma maneira de lê-lo melhor, mais a fundo, por dentro. Coisa que, depois de tudo, é o que justifica todo intento legítimo de tradução de poesia.

No último ano o senhor ganhou muitos prêmios, tanto na Argentina quanto no Brasil. Quais são seus planos para o futuro? Guarda alguma obra inédita ou em curso? 
Nunca me pareceu razoável que a dimensão de uma obra se meça apenas pelas recompensas que se recebe. Se bem que não se sabe - quanto de azar, de coincidência, pode haver nestas questões. Para mim os prêmios somente admitem relevância quando foram gerados espontaneamente, sem estratégia e sem astúcia. E de maneira especial quando os colegas os produzem, escritores, que muitas vezes nem se conhecem. Como bem reiterou Paul Valéry: "As maiores glórias imagináveis em uma glória é a que permanecerá sempre ignorada daquele que a obtém". Ou, melhor ainda, "A glória deve obter-se como subproduto". De forma mais modesta, porém mais precisa, também antecipou José Pedroni: "A glória é um verso recordado." O generoso, invalorável reconhecimento de meu querido Brasil, tem sido uma das maiores emoções de minha vida: um autêntico caso de amor correspondido. Por certo, um verdadeiro escritor sempre tem de ter algo inédito, que não se anima a publicar. Porém, eu necessito que os poemas, por exemplo, me digam eles mesmos e que me façam sentir se adotaram a forma de livro. E isso me faz esperá-los, dar-lhes seu tempo. Em meu caso em particular, por outro lado, existe uma certa quantidade de textos em prosa, muitas vezes de circunstância ou de intervenção, que me pedem para não desaparecer com as páginas de revista ou do periódico onde geralmente foram publicados. Uma parte deles tem voltado a tomar recentemente forma de livros: A voz sem amo é um, e República de vento outro, que já estão em processo de edição. Encanta-me, e às vezes me assusta, me paralisa, que houvesse editores que continuassem publicando minha poesia completa, da qual já apareceu milagrosamente um primeiro tomo, que reedita meus seis primeiros livros e cujo título, A favor do vento, imagino também para todo o conjunto. Dá-me uma enorme alegria que antologias de minha poesia continuem aparecendo em países queridos e irmãos: existem duas em execução no México e no Chile, e outro projeto previsto na Venezuela. Porém, me agradaria também ser lido na pátria do meu sangue, Espanha, e nas outras duas pátrias de meu espírito, Brasil e Itália. Dirão os deuses. Eu me deixo levar.

Buenos Aires, 31 de janeiro de 2006. 